\title{
PENGEMBANGAN SISTEM PENDUKUNG KEPUTUSAN UNTUK MENGETAHUI KECENDRUNGAN SEORANG MAHASISWA DALAM MENGAMBIL MATA KULIAH PILIHAN DALAM LINGKUP PENDIDIKAN TEKNIK INFORMATIKA DAN KOMPUTER MENGGUNAKAN ALGORITMA APRIORI
}

\author{
Hanifa Dian Permatasari ${ }^{1}$, Widodo $^{2}$, Bambang Prasetya Adhi ${ }^{3}$ \\ ${ }^{1}$ Mahasiswa Prodi PendidikanTeknik Informatika dan Komputer, Teknik Elektro, FT - UNJ \\ ${ }^{2,3}$ Dosen Prodi Pendidikan Teknik Informatika dan Komputer, Teknik Elektro, FT - UNJ \\ 'hanipanip.hd@gmail.com, ${ }^{2}$ widodo@ unj.ac.id ${ }^{3}$ bambangpadhi@unj.ac.id
}

\begin{abstract}
Abstrak
Penelitian ini bertujuan untuk mengembangkan sistem pendukung keputusan untuk mengetahui kecendrungan seorang mahasiswa dalam mengambil mata kuliah pilihan dalam lingkup Program Studi Pendidikan Teknik Informatika dan Komputer menggunakan algoritma apriori. Metode penelitian yang digunakan adalah pengembangan RnD (Research and Development) dengan model perangkat lunak Waterfall. Tahapan penelitian yang dilakukan terdiri dari: (1) Requirement Definition; (2) System and Software Design; (3) Implementation and Unit Testing; (4) Integration and System Testinge. Hasil yang didapatkan akan selalu berbeda dan bergantung kepada input user pada saat pembuatan aturan. Sistem pendukung keputusan ini memproses data transaksi mata kuliah mahasiswa Program Studi Pendidikan Teknik Informatika dan Komputer semester 106, dan menghasilkan aturan asosiasi tertinggi untuk \{praktek industri, data mining, metode penelitian\} $\rightarrow\{$ pengolahan citra\} dengan confidence sebesar 96,3\%. Sistem memerlukan data dalam jumlah besar dan spesifikasi perangkat seperti prosesor, RAM, dan server xampp agar prediksi aturan asosiasi yang dihasilkan semakin baik. Berdasarkan uji kelayakan menggunakan black box didapatkan hasil bahwa sistem telah berjalan dengan baik sesuai kebutuhan fungsional.
\end{abstract}

Kata kunci : Sistem Pendukung Keputusan, Aturan Asosiasi, Algoritma Apriori

\section{Pendahuluan}

Pada jenjang pendidikan di perguruan tinggi, sistem perkuliahan mengatur administrasi akademiknya masing-masing. Termasuk dalam pengambilan mata kuliah di setiap instansi perguruan tinggi pun berbeda. Terdapat syarat tertentu seperti penentuan SKS (Satuan Kredit Semester) untuk menyelesaikan jenjang pendidikan yang sudah disiapkan oleh instasi perguruan tinggi. Mata kuliah yang disiapkan pun tentunya disesuaikan dengan jurusan dan program studi yang bersangkutan. Oleh karena itu mahasiswa hendaknya paham mengenai syarat- syarat dalam pengambilan mata kuliah. Untuk mata kuliah pilihan, mahasiswa diberikan beberapa pilihan di setiap semester ganjil maupun semester genap, namun mahasiswa hanya perlu menyelesaikannya minimal sebanyak 13 SKS

Mahasiswa dapat memilih mata kuliah pilihan sesuai dengan keinginan mereka, mata kuliah pilihan bisa diambil di awal tahun masuk ataupun di pertengahan tahun masuk. Sehingga mahasiswa bisa memberi batasan pada jenis mata kuliah pilihan yang akan diambil per-semesternya. Namun dikarenakan total mata kuliah pilihan yang harus diambil, minimal
13 SKS sampai dengan semester ke- 8 memungkinkan adanya kelas mata kuliah pilihan yang terisi penuh atau kurang dari syarat minimal dibukanya kelas.

Mata kuliah pilihan akan diganti dan tentunya tidak sama dengan semester sebelumnya. Dengan melihat antusias mahasiswa di semester sebelumnya kemungkinan untuk membaca pola pada mata kuliah pilihan yang dipilih mahasiswa akan lebih membantu Koordinator Program Studi Pendidikan Teknik Informatika dan Komputer dalam hal ini. Kasus ini dapat diselesaikan dengan dibuatnya sistem pendukung keputusan menggunakan penerapan algoritma apriori dan menemukan aturan asosiasi yang terjadi pada pengambilan mata kuliah oleh mahasiswa.

Dalam membuka kelas mata kuliah pilihan, Koordinator Program Studi Pendidikan Teknik Informatika dan Komputer belum berdasarkan pada pola pengambilan mata kuliah pilihan oleh mahasiswa. Hal ini menyebabkan kelas yang dibuka tidak memenuhi jumlah minimal peserta. Oleh karena perlu dikembangkan sistem pendukung keputusan untuk mengetahui pola mahasiswa dalam mengambil mata kuliah pilihan berdasarkan aturan asosiasi yang 
dihasilkan. Sistem ini digunakan sebagai pertimbangan Koordinator Program Studi Pendidikan Teknik Informatika dan Komputer dalam membuka kelas mata kuliah pilihan agar tidak ada kelas yang ditutup di Program Studi Pendidikan Teknik Informatika dan Komputer

\section{Dasar Teori}

\subsection{Definisi Data}

Sutanta (2011) Data dapat didefinisikan sebagai bahan keterangan tentang kejadian-kejadian nyata atau fakta-fakta yang dirumuskan dalam sekelompok lambang tertentu yang tidak acak, yang menunjukan jumlah, tindakan, atau hal.

\subsection{Definisi Data Mining}

Tan, et al (2006) Data mining adalah proses yang secara otomatis menemukan informasi berguna pada data yang tersimpan dalam jumlah besar. Teknik data mining digunakan untuk memeriksa apakah ditemukan pola berguna yang mungkin tidak pernah diketahui dalam basis data besar. Selain itu data mining juga dapat digunakan untuk memprediksi masa depan seperti memprediksi pelanggan yang akan menghabiskan lebih dari seratus dolar untuk berbelanja di department store.

\subsection{Algoritma Apriori}

Kaufmann (2012: 248) apriori diusulkan oleh R. Agrawal \& R. Srikant pada tahun 1994 untuk melakukan mining frequent itemset di Bolean Association Rule. Algoritma apriori termasuk jenis aturan asosiasi pada data mining, dengan menemukan aturan asosiatif antara suatu kombinasi item. Istilah yang sering digunakan dalam aturan asosiasi menggunakan algoritma apriori adalah itemset, $k$ itemset, support, confidence, minsup, dan frequent itemset.

\subsection{Asosiasi}

Tan, et al (2006) aturan asosiasi adalah ekspresi implikasi dari X maka Y, dimana X dan Y bukan itemset yang sama. Ukuran aturan asosiasi yang kuat dapat dilihat dari support dan confidence. Han, et al (2012) secara umum untuk mendapatkan aturan asosiasi ditentukan dengan dua proses yaitu: (1) Menemukan semua frequent itemset; (2) Membuat aturan asosiasi kuat yang berasal dari frequent itemset. Artinya aturan yang dibuat harus memenuhi minimal support dan minimal confidence.

\subsection{Sistem Pendukung Keputusan}

Kurniasih (2013) sistem pendukung keputusan merupakan pengembangan lebih lanjut dari sistem informasi manajemen terkomputerisasi yang dirancang sedemikian rupa sehingga bersifat interaktif. Turban (2005) sistem pendukung keputusan adalah sistem yang diharapkan mampu mendukung dalam membuat keputusan pada situasi yang bersifat semi-terstruktur.

\section{Metodologi}

\subsection{Tempat dan Waktu Penelitian}

Penelitian ini dilakukan di Fakultas Teknik, Program Studi Pendidikan Teknik Informatika dan Komputer, Universitas Negeri Jakarta yang berlokasi di Jl. Rawamangun Muka Rt 11 / RW 14 Rawamangun Jakarta Timur. Penelitian ini dilakukan pada bulan Juni 2018 hingga bulan Desember 2018.

\subsection{Metode Pengembangan Produk}

\subsubsection{Tujuan Pengembangan}

Tujuan dari penelitian ini adalah pengembangan sistem pendukung keputusan bagi Koordinator Program Studi Pendidikan Teknik Informatika dan Komputer dalam mengambil keputusan untuk mengetahui kecendrungan mahasiswa dalam mengambil mata kuliah pilihan. Dengan mengetahui kecendrungan mahasiswa, sistem ini hendaknya digunakan sebagai pengambilan keputusan dalam membuka kelas mata kuliah pilihan. Sistem ini dapat digunakan oleh pemangku kepentingan yang berhak dalam menentukan dibukanya kelas mata kuliah pilihan agar tidak ada kelas yang ditutup karena tidak memenuhi syarat minimal dibukanya kelas.

\subsubsection{Metode Pengembangan}

Dalam mengembangkan sistem ini, digunakan metode Research and Development untuk mencapai keberhasilan berdasarkan kebutuhan fungsional. Aturan asosiasi digunakan untuk membaca pola hubungan yang erjadi pada mahasiswa dalam mengambil mata kuliah pilihan. Sistem ini diharapkan mampu membantu Koordinator Program Studi Pendidikan Teknik Informatika dan Komputer dalam membuat keputusan untuk membuka mata kuliah pilihan yang paling diminati berdasarkan kecendrungan mahasiswa di semester sebelumnya.

\subsection{Prosedur Pengembangan}

\subsubsection{Requirement Definition}

Daftar kebutuhan untuk mengembangkan sistem pendukung keputusan. Gambaran umum tentang sistem yang akan dikembangkan adalah sebagai berikut.

a. Sistem dapat melakukan login dan logout.

b. Sistem dapat menentukan nilai minimal support dan minimal confidence.

c. Sistem dapat memasukan data transaksi.

d. Sistem dapat melakukan proses mining pada data transaksi mata kuliah mahasiswa.

e. Sistem dapat menampilkan hasil mining berupa aturan asosiasi. 


\subsubsection{Design}

Pada tahap ini, dibuat model rancangan dari sistem yang akan dikembangkan menggunakan DFD, ERD yang ditunjukan pada Gambar 3.1,Gambar 3.2, dan Gambar 3.3.

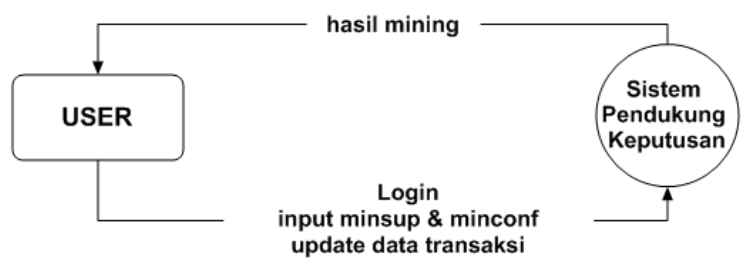

Gambar 3.1 DFD Level 0 Sistem Pendukung Keputusan

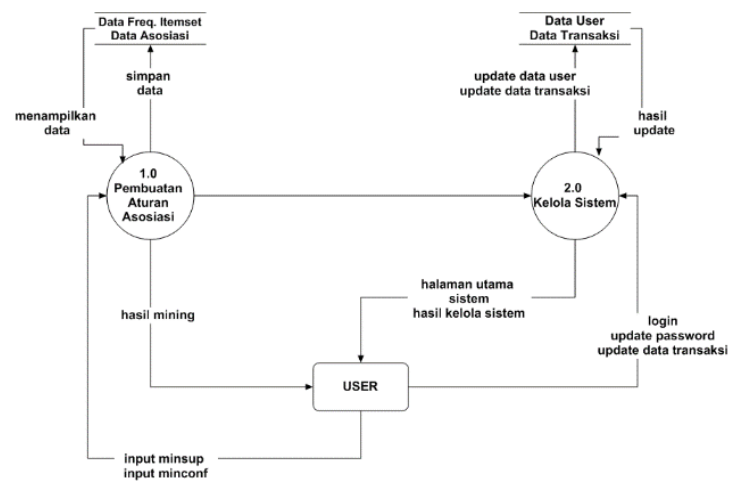

Gambar 3.2 DFD Level 1 Sistem Pendukung Keputusan

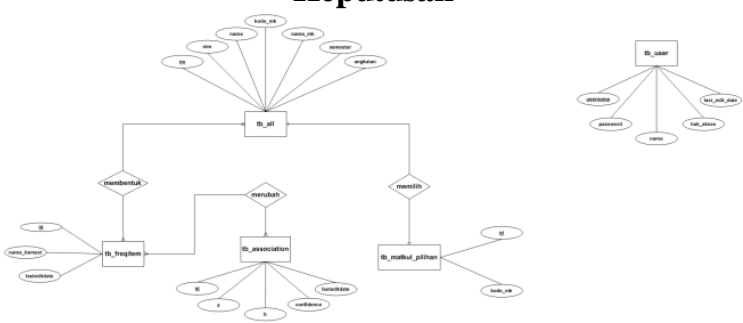

Gambar 3.3 ERD Sistem Pendukung Keputusan

\subsubsection{Implementation}

a. Rancangan Halaman Login

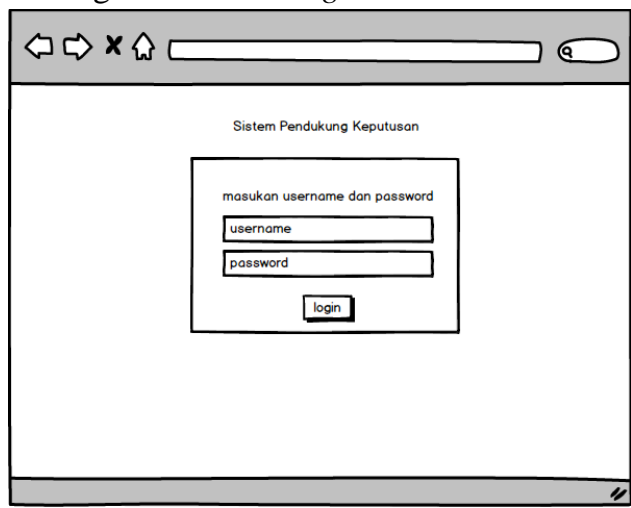

Gambar 3.4 Rancangan Halaman Login b. Rancangan Halaman Utama

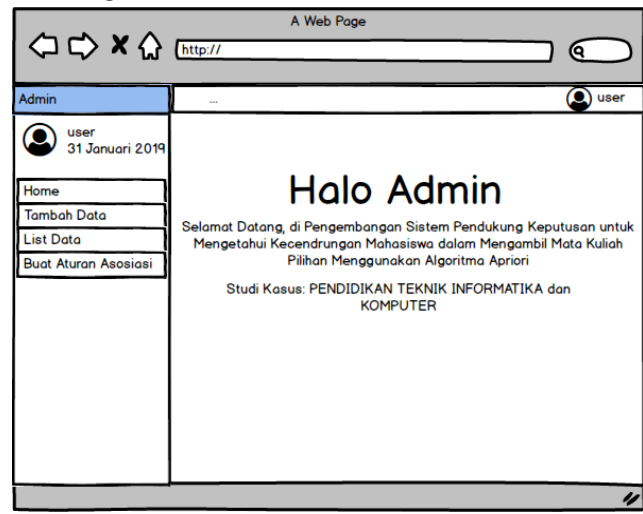

Gambar 3.5 Rancangan Halaman Utama

\section{Hasil dan Analisis}

\subsection{Hasil Pengembangan Produk}

Hasil dari penelitian ini adalah sistem pendukung keputusan untuk mengetahui kecendrungan seorang mahasiswa dalam mengambil mata kuliah pilihan berbasis web. Digunakan oleh Koordinator Program Studi Pendidikan Teknik Informatika dan Komputer sebagai bahan pertimbangan dalam mebuka kelas mata kuliah pilihan. Sistem ini menggunakan model waterfall dalam pengembangannya. Tahapan yang berhasil dicapai dalam pengembangan sistem adalah Requirement System, System and Software Design, Implementation and Unit Testing, dan Integration and System Testing.

\subsection{Hasil Aturan Asosiasi}

Hasil dari sistem pendukung keputusan ini berupa aturan asosiasi yang dapat digunakan Koordinator Pendidikan Teknik Informatika sebagai pertimbangan dalam membuka kelas mata kuliah pilihan pada semester selanjutnya. Gambar 4.1 hingga Gambar 4.4 adalah beberapa percobaan yang dilakukan dengan input berbeda:

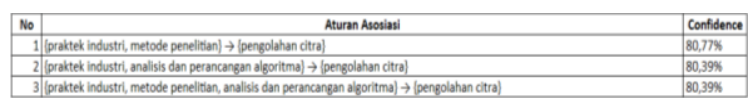

Gambar 4.1 Hasil Aturan Asosiasi Percobaan Pertama

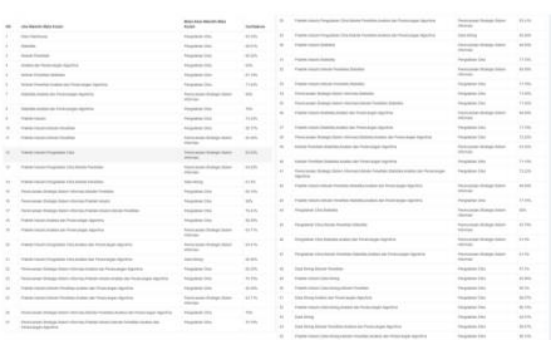

Gambar 4.2 Hasil Aturan Asosiasi Percobaan Kedua 


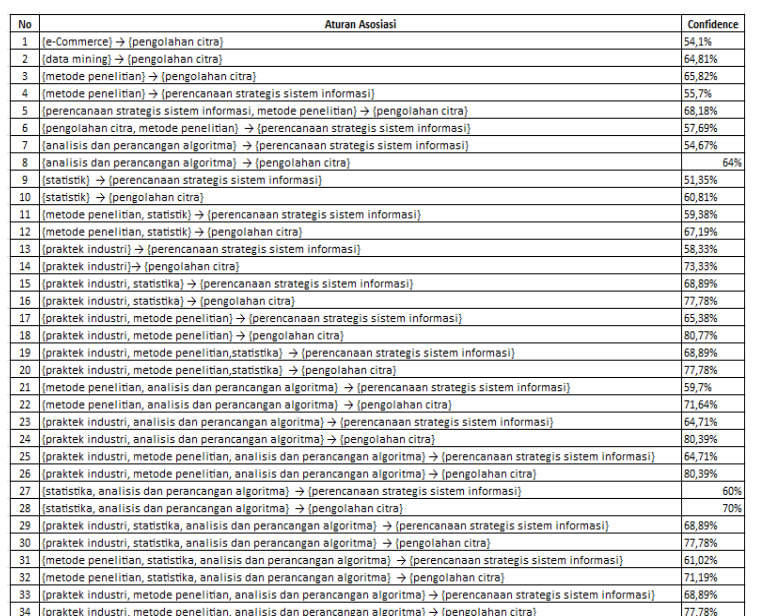

Gambar 4.3 Hasil Aturan Asosiasi Percobaan

\subsection{Pembahasan}

\section{Ketiga}

\subsubsection{Pembahasan Tampilan}

Berdasarkan rancangan yang telah dibuat maka hasil dari tampilan sistem ditunjukkan pada Gambar 4.1 dan halaman login ditujukkan pada Gambar 4.2:

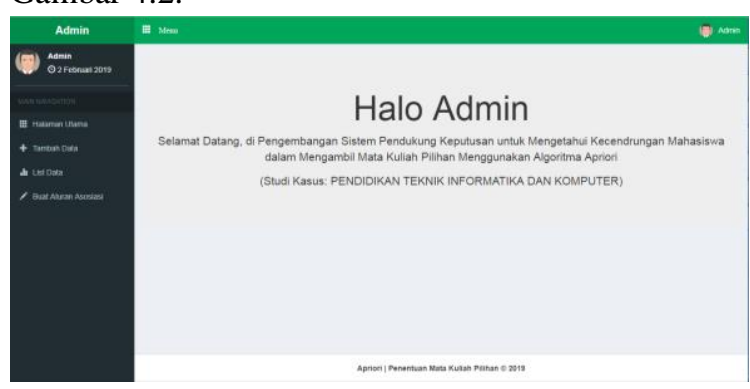

Gambar 4.1 Halaman Utama

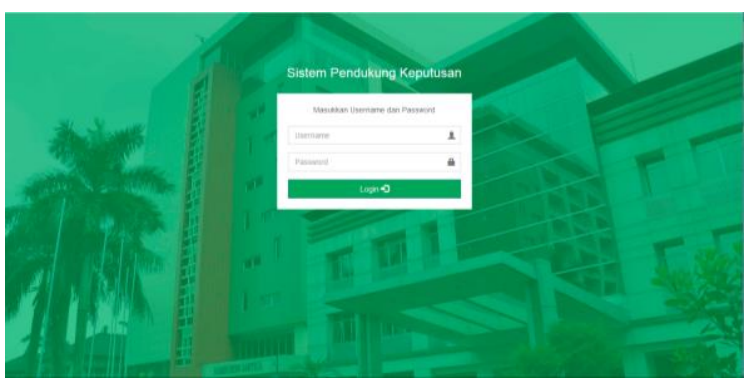

Gambar 4.1 Halaman Login

\subsubsection{Pembahasan Pengujian Kebutuhan Fungsional}

Sistem pendukung keputusan telah dilakukan pengujian dan sesuai dengan hasil pengujian kebutuhan penggunanya. Sistem memiliki satu level pengguna yaitu Koordinator Program Studi Pendidikan Teknik Informatika dan Komputer. Dimulai dengan proses login menggunakan username $=$ admin dan password $=$ admin123. Setelah berhasil masuk, user diarahkan ke halaman utama kemudian menggunakan fitur buat aturan asosiasi. Pada fitur ini user mengisikan nilai minimal support $=30$ dan minimal confidence $=50 \%$ kemudian menekan tombol proses. Kemudian user masuk ke halaman hasil pertama lalu ke halaman hasil asosiasi, lalu user logout dari sistem.

\subsubsection{Pembahasan Pembuatan Aturan Asosiasi}

Sistem pendukung keputusan ini dibuat menggunakan bahasa pemrograman PHP, server xampp versi 5.6.4, database MySQL, dan spesfikasi laptop intel(R) Pentium(R) 2.4Ghz; 4GB Ram. Dengan spesifikasi laptop tersebut, data transaksi mahasiswa yang bisa digunakan untuk melakukan proses mining hanya sebanyak 1724 data/baris. Untuk memperbaharui dan melakukan proses mining pada data tersebut, sistem memerlukan waktu sekitar 2 sampai 3 menit. Data yang digunakan adalah data semester 106 yang terdiri dari angkatan 2010 semester 14, angkatan 2011 semester 12, angkatan 2012 semester 10, angkatan 2013 semester 8, angkatan 2014 semester 6, dan angkatan 2015 semester 4. Pembuatan aturan asosiasi memerlukan dua parameter dalam proses mining, sehingga hasil yang diperoleh selalu berbeda dan bergantung kepada input user.

\section{Kesimpulan dan Saran \\ 5.1 Kesimpulan}

Hasil penelitian dan pengembangan berupa sistem pendukung keputusan yang dibuat menggunakan algoritma apriori untuk menghasilkan aturan asosiasi yang dapat digunakan sebagai bahan pertimbangan dalam membuka kelas mata kuliah pilihan oleh Koordinator Program Studi Pendidikan Informatika dan Komputer. Menggunakan waterfall model namun tahapan yang berhasil dicapai hanya sampai integration and system testing. Aturan asosiasi tertinggi yang didapatkan melalui empat kali percobaan adalah \{praktek industri, data mining, metode penelitian $\} \rightarrow\{$ pengolahan citra $\}$ dengan confidence sebesar $96,3 \%$.

\subsection{Saran}

Berdasarkan hasil dan kesimpulan dari skripsi ini, diharapkan kepada peniliti lain yang ingin melakukan penelitian sejenis disarankan untuk menggunakan algoritma FP-Growth sebagai perluasan dari algoritma apriori untuk menghindari komputasi yang kompleks berdasarkan faktor batasan support, dan banyaknya items yang diproses. Menggunakan data yang lebih banyak agar hasil prediksi sistem semakin baik. Mempertimbangkan spesifikasi perangkat yang akan digunakan seperti processor, RAM, dan server xampp jika data transaksi mata kuliah yang diproses dalam jumlah besar. Memperbaiki fitur yang belum sempurna atau menambahkan fitur lain untuk memperbaiki kinerja sistem 


\section{Daftar Pustaka :}

[FT] Fakultas Teknik. 2009. Pedoman Penelitian Skripsi. Jakarta: Fakultas Teknik, Universitas Negeri Jakarta.

Han, J., Kamber, M., Pei, J. (2012) Data Mining Concepts and Technique. Ed ke-3. USA: Elsevier Inc.

Hermawati, F. A. (2013). Data Mining. Yogyakarta: Andi.

Kurniasih. (2013). Sistem pendukung keputusan pemilihan laptop dengan metode topsis. Pelita Informatika Budi Darma, Volume III Nomor 2:6-13.

Lestari, T. 2009. Analisis Keranjang Belanja pada Data Transaksi Penjualan (Studi Kasus Toserba Yogya Banjar)[skripsi]. Bogor: Fakultas Ekonomi dan Manajemen, Institut Pertanian Bogor.

Ngoen, S.T. (2009) Algoritma dan Struktur Data Bahasa C. Jakarta: Mitra Wacana Media.

Olson, D. \& Shi, Y. (2007). Introduction to Business Data Mining. Terjemahan oleh Sungkono, C.; editor oleh Tim SPSS Indonesia. Jakarta: Salemba Empat.

Pressman, R. S. (2012). Rekayasa Perangkat Lunak. Ed ke-7. Yogyakarta: Andi.

Randolf. 2008. Penerapan Metode Kaidah Asosiasi pada Data Transaksi Minimarket dengan Menggunakan Algoritma Apriori[skripsi]. Depok: Fakultas Matematika dan Ilmu Pengetahuan Alam Departemen Matematika, Universitas Indonesia.

Saputro, G.A. 2017. Penerapan Algoritma Apriori untuk Mencari Pola Penjualan di Cafe Studi Kasus: Jurney Coffee[skripsi]. Yogyakarta: Fakultas Sains dan Teknologi, Universitas Sanata Dharma.

Sommerville, I. (2011). Software Engineering. Ed ke9. Boston: Pearson Education Inc.

Sutanta, E. (2011). Basis Data dalam Tinjauan Konseptual. Yogyakarta: Andi.

Tan, P., Steinbach, M., Kumar, V. (2006). Intoduction To Data Mining. Boston: Pearson Education Inc.

Tim Penyusun Fakultas Teknik UNJ. (2014). Pedoman Akademik 2014/2015 Fakultas Teknik Universitas Negeri Jakarta. Jakarta: Gedung L, Fakultas Teknik, Universitas Negeri Jakarta

Turban, E., Aronson, J.E., Liang, T. (2005) Decision Support System and Intelligence System. Ed ke-7. New Delhi: Prentice-Hall Inc. 